Известия Саратовского университета. Новая серия. Серия: Науки о Земле. 2021. Т. 21, вып. 2. С. 103-117

Izvestiya of Saratov University. Earth Sciences, 2021, vol. 21, iss. 2, pp. 103-117

Научная статья

УДК 563.45(116.3:470.4)

https://doi.org/10.18500/1819-7663-2021-21-2-103-117

\title{
Род Tremabolites Zittel, 1878 (Porifera, Hexactinellida)
}

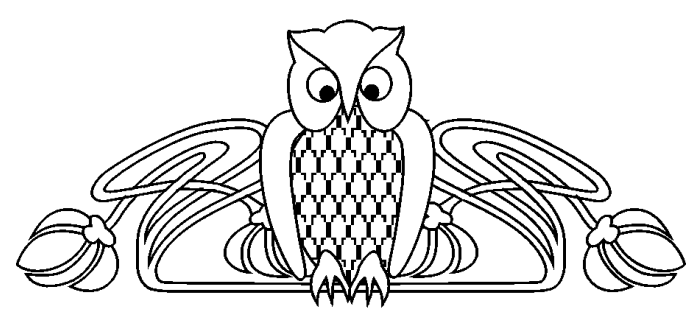

\section{Е. М. Первушов}

Саратовский национальный исследовательский государственный университет имени Н. Г. Чернышевского, Россия, 410012, г. Саратов, ул. Астраханская, д. 83

Первушов Евгений Михайлович, доктор геолого-минералогических наук, pervushovem@mail.ru, http://orcid.org/0000-0002-7962-0274

\begin{abstract}
Аннотация. Губки Tremabolites, известные из средне-, позднемеловых отложений Европы, уверенно идентифицируются благодаря многочисленным отверстиям на гладкой верхней поверхности скелета. Представления об уровне организации этих губок и о характеристике видов не столь однозначны. Рассмотрено видовое разнообразие Tremabolites, распространенных в коньякских - сантонских породах Поволжья. Приведены примеры регенерации и почкования среди представителей группы.

Ключевые слова: губки, гексактинеллиды, Tremabolites, транситорные колонии, регенерация, почкование, верхний мел

Для цитирования: Первушов E. М. Род Tremabolites Zittel, 1878 (Porifera, Hexactinellida) // Известия Саратовского университета. Новая серия. Серия: Науки о Земле. 2021. Т. 21, вып. 2. С. 103-117. https://doi.org/10.18500/1819-7663-2021-21-2-103-117
\end{abstract}

Статья опубликована на условиях лицензии Creative Commons Attribution License (CC-BY 4.0)

Article

https://doi.org/10.18500/1819-7663-2021-21-2-103-117

Genus Tremabolites Zittel, 1878 (Porifera, Hexactinellida)

\section{E. M. Pervushov}

Saratov State University, 83 Astrakhanskaya St., Saratov 410012, Russia

Evgeniy M. Pervushov, pervushovem@mail.ru, http://orcid.org/0000-0002-7962-0274

Abstract. Tremabolites sponges known among the Middle-Late Cretaceous beds in Europe are reliably identifiable due to the numerous openings against the background of the skeleton smooth upper surface. The ideas of the level of organization in these sponges and of the species characteristics are far from being univocal. The paper deals with the species diversity of Tremabolites common in the Coniacian - Santonian rocks from the Volga Region. Examples of regeneration and budding in the representatives of the group are presented.

Keywords: sponges, Hexactinellida, Tremabolites, transitory colonies, regeneration, budding, Upper Cretaceous

For citation: Pervushov E. M. Genus Tremabolites Zittel, 1878 (Porifera, Hexactinellida). Izvestiya of Saratov University. Earth Sciences, 2021, vol. 21, iss. 2, pp. 103-117 (in Russian). https://doi.org/10.18500/1819-7663-2021-21-2-103-117

This is an open access article distributed under the terms of Creative Commons Attribution License (CC-BY 4.0)

\section{Введение}

Из трех десятков местонахождений собрано более двухсот скелетов губок, отнесенных к роду Tremabolites. Из них несколько форм выделены из карбонатных пород среднего коньяка, а большая часть фоссилий - из сантонских отложений Поволжья.

Губки Tremabolites рассматриваются в качестве настоящих транситорных колоний [1]. Транситории - переходные формы между унитарными и колониальными формами, которые характеризуются наличием многочисленных субоскулюмов (дополнительных оскулюмов) на внешней поверхности элементов скелета губок. От основания скелета Tremabolites поднимаются дихотомирующие ветви, которые открываются на общей верхней поверхности многими оскулюмами, что и позволяет относить их к колониальным формам (рис. 1).

Многочисленные круглые оскулюмы на ровной верхней поверхности - характерная черта скелетов Tremabolites, что позволяет достоверно идентифицировать этих представителей гексактинеллид на уровне рода. Для описания скелетов данных губок не разработан терминологический 


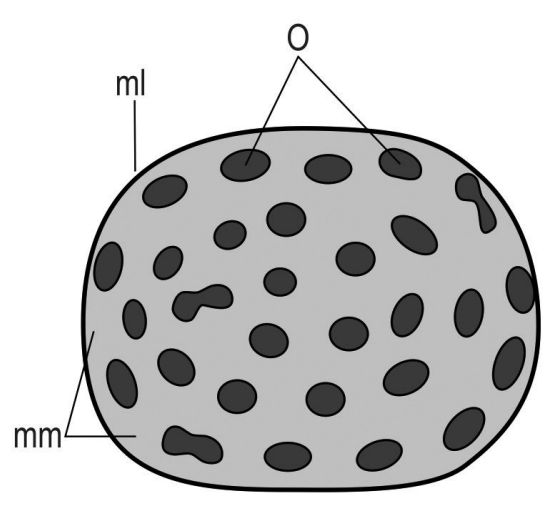

1a

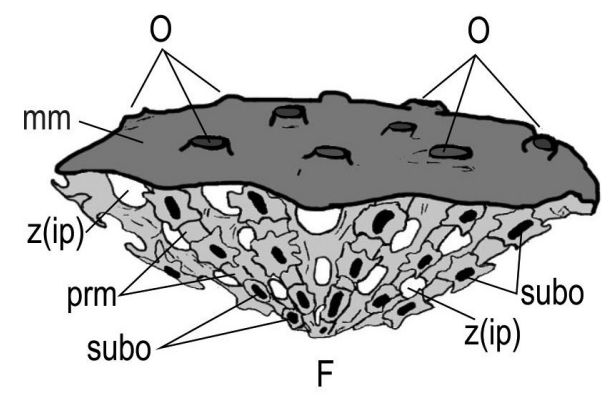

$1 \mathrm{~B}$

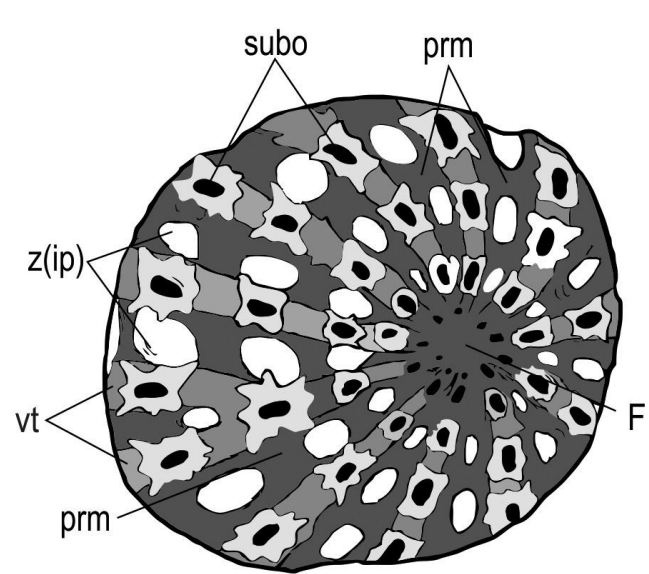

16

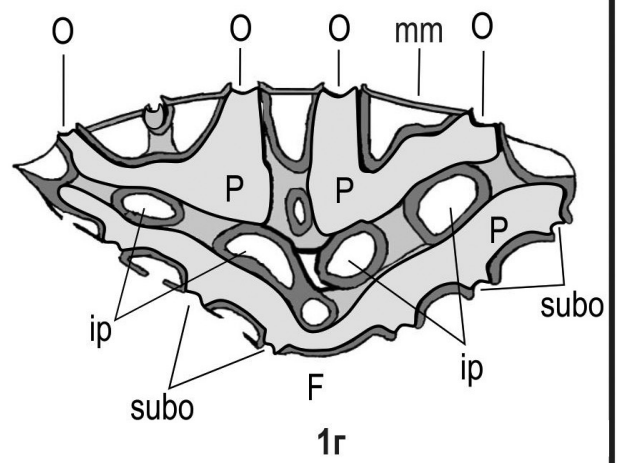

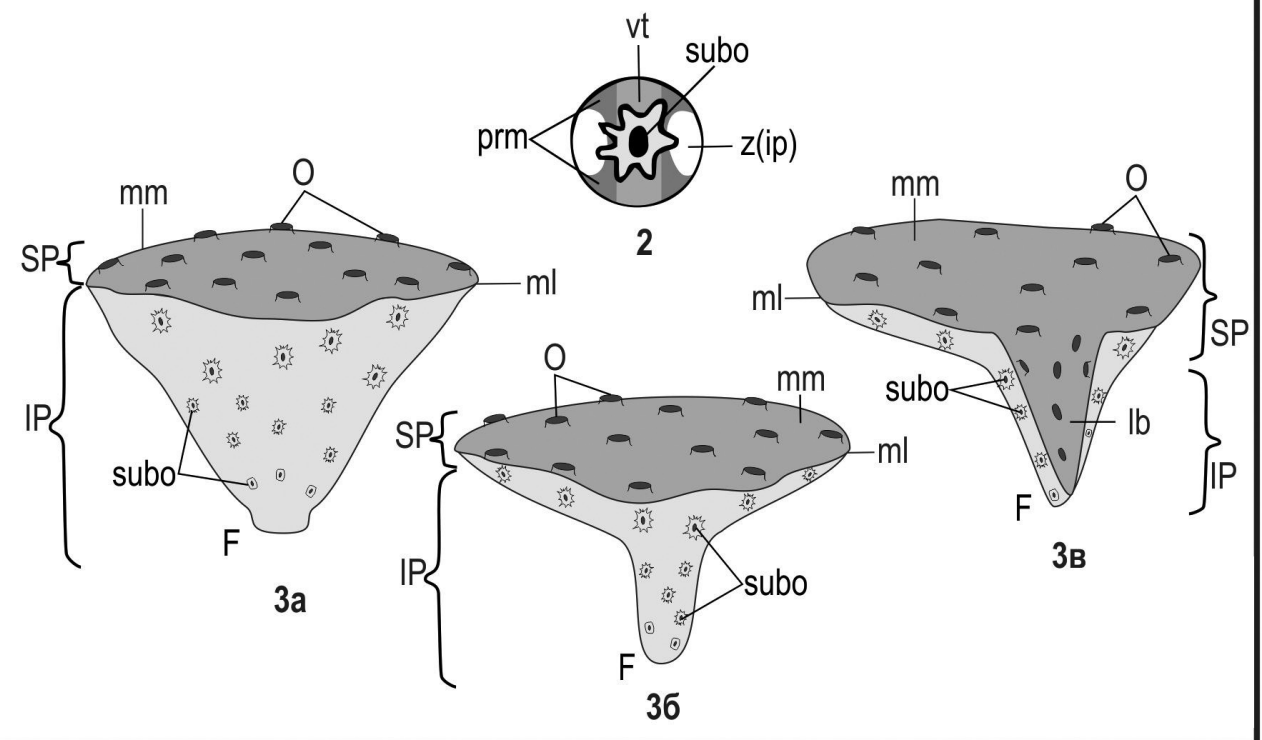

Рис. 1. Морфология скелета представителей рода Tremabolites Zittel, 1877. Фиг. 1. Tremabolites megastome (Roemer, 1841): $1 \mathrm{a}$ - вид сверху, 16 - снизу, 1в - сбоку, 1г - схема внутреннего строения скелета при вертикальном его сечении. Фиг. 2. Внешнее обрамление одного из субоскулюмов, расположенных на внешней поверхности ветвей в нижнем сегменте скелета. Фиг. 3. Строение верхнего и нижнего сегментов и их соотношение в структуре скелета Tremabolites Zittel, 1877: $3 \mathrm{a}$ - высокое ширококоническое основание и субплоская кортикальная мембрана, 3б - центральное положение узкого высокого основания при изометричном строении кортикальной мембраны, Зв - смещенное к периферии положение узкого основания и асимметричное строение кортикальной мембраны, спускающейся до основания скелета. Условные обозначения: F - основание скелета, IP - нижний сегмент скелета, O - оскулюмы, Р - сегменты парагастральной полости, SP - верхний сегмент скелета, $\mathrm{mm}$ - кортикальная мембрана (верхняя поверхность), ір - интерлабиринтовое пространство, $\mathrm{lb}$ - ложбина, $\mathrm{ml}$ - маргинальная линия (верхний край), prm - перемычки, subo - субоскулюмы, vt - ветви, z (ip) - зияния. Черный цвет - оскулюмы и субоскулюмы, темно-серый оттенок - кортикальная мембрана, светло-серый оттенок - нижний сегмент скелета, белый цвет - зияния и сегменты интерлабиринтового пространства 
аппарат, а используемый предшествующими исследователями при характеристике фоссилий иллюстративный материал несет информацию лишь о принадлежности к роду Tremabolites.

Помимо представления реалистичных изображений рассматриваемых фоссилий в двух-трех ракурсах (фототабл. 1-7), исходя из опыта предыдущих изысканий $[1,2]$, текст их описаний актуально сопровождать схематичными рисунками известных в составе рода видов (рис. 2). В строении Tremabolites отчетливо выделяются верхняя и нижняя части скелета. Верхняя часть это кортикальная мембрана с окулюмами, которая у некоторых форм спускается до основания губки (см. рис. 1). Нижняя часть скелета образована ветвями, на внешней поверхности которых расположены субоскулюмы. Граница между этими частями скелета морфологически четко очерчена верхним краем - контуром кортикальной мембраны. Выше верхнего края субоскулюмы отсутствуют, а ниже нет оскулюмов. На кортикальной мембране, близ ее верхнего края, встречаются не успевшие отделиться почки, а от ветвей нижней части скелета формируются дополнительные опорные выросты.

Для скелетов овальных очертаний, которые могут быть охарактеризованы одной или двумя плоскостями симметрии, используются понятия латусных (широких) и ангустатных (узких) сторон. Одна из латусных сторон при асимметричном строении скелета рассматривается как фронтальная, предположительно ориентированная на направление течения, а противоположная - как тыльная. На фронтальной стороне скелета некоторых форм развивается ложбина, спускающаяся до основания губки, которое разделяет два фронтальных периферийных выроста (см. рис. 2).

При описании фоссилий использованы материалы отечественных [3-7] и зарубежных исследователей [8-24].

\section{Описание}

Тип Hexactinellida

Подотряд Lychniscosa A. Schrammen, 1903

Семейство Camerospongiidae A. Schrammen, 1912

Диагноз. Скелеты образованы тонкостенными (до $1-2$ мм) дихотомирующими ветвями или сателлитами, составляющими скелеты лабиринтового строения, колониальной и транситорной организации.

Cостав. Camerospongiini, Tremabolitini, Becksiini, Plocoscyphiini.

Подсемейство Tremabolitini Zittel, 1877

Диагноз. Губки транситорного уровня организации - на внешней поверхности ветвей скелета расположены овальные субоскулюмы.

Состав. Tremabolites Zittel, 1877; ? Camerospongia Krupp, 2010.
Сравнение. От Сamerospongiini отличается наличием субоскулюмов.

\section{Род Tremabolites Zittel, 1877}

Manon - Roemer, 1841, c. 3.

Cephalites - T. Smith, 1848, c. 294; - Treathis ..., 2004, c. 524. c. 669 .

Coeloptychium - Fischer von Waldheim, 1843,

Etheridgia - Tate, 1864 , с. 42-43; - Основы ..., 1962, c. 44.

Camerospongia - Schluter, 1872, c. 19, 27.

Tremabolites - Zittel, 1877 , c. 56; - Leonard, 1897 , c. 36 ; - Defretin-Lefranc, 1958, c. 93; Трестьян, 1973, с. 10; - Konig, 1988, с. 39; Swierczewska-Gladysz, 2006, c. 269.

Maeandroptychium - Синцов, 1879, с. 10.

Plocoscyphia - Dunicowski, 1888, c. 83.

Типовой вид - Manon megastoma Roemer, 1841, верхний мел. Германия.

Диагноз. Скелет образован несколькими ветвями, дихотомирующими в вертикальной плоскости, за счет чего его диаметр увеличивается по направлению вверх. Тонкая гладкая кортикальная мембрана перекрывает интерлабиринтовое пространство скелета сверху. Кортикальная мембрана оконтуривает оскулюмы, порой возвышающиеся над ней. Оскулюмы округлых очертаний, а при объединении двух полостей - гантевидные, расположены концентрически или хаотично. Количество оскулюмов соотносится с размерами скелета, площадью верхней его части и достигает максимально 30. Диаметр оскулюмов изменяется в пределах 2-5 мм. У единичных форм, обитавших в условиях активной гидродинамики, диаметр немногочисленных оскулюмов достигает 10-12 мм. Диаметр оскулюмов различен в строении одного скелета, и обычно самые мелкие из них приурочены к периферии верхней поверхности.

Под верхним краем кортикальной мембраны расположена нижняя часть скелета. Это трубковидные ветви (модули), поднимающиеся вверх от точечного основания, дихотомирующие и соединяющиеся между собой одинаковыми по размерам перемычками. На внешней поверхности ветвей расположены многочисленные овальные субоскулюмы, диаметр которых возрастает от основания скелета (1-3 мм). Между ветвями и перемычками прослеживаются зияния, ведущие в интерлабиринтовое пространство внутри скелета губки. Ажурная сеть выростов, исходящих от субоскулюмов, расположенных на соседних ветвях, прикрывает зияния и образует поверхность нижней части скелета.

Ризоиды не выявлены. Многие представители рода свободно находились на поверхности осадка. Для этих форм характерно коническое основание скелета, редко стержнеобразное. Распространено прикрепление губок к твердым элементам субстрата - фрагментам скелетов погибших губок (Guettardiscyphia, Zittelispongia) или абиогенным 


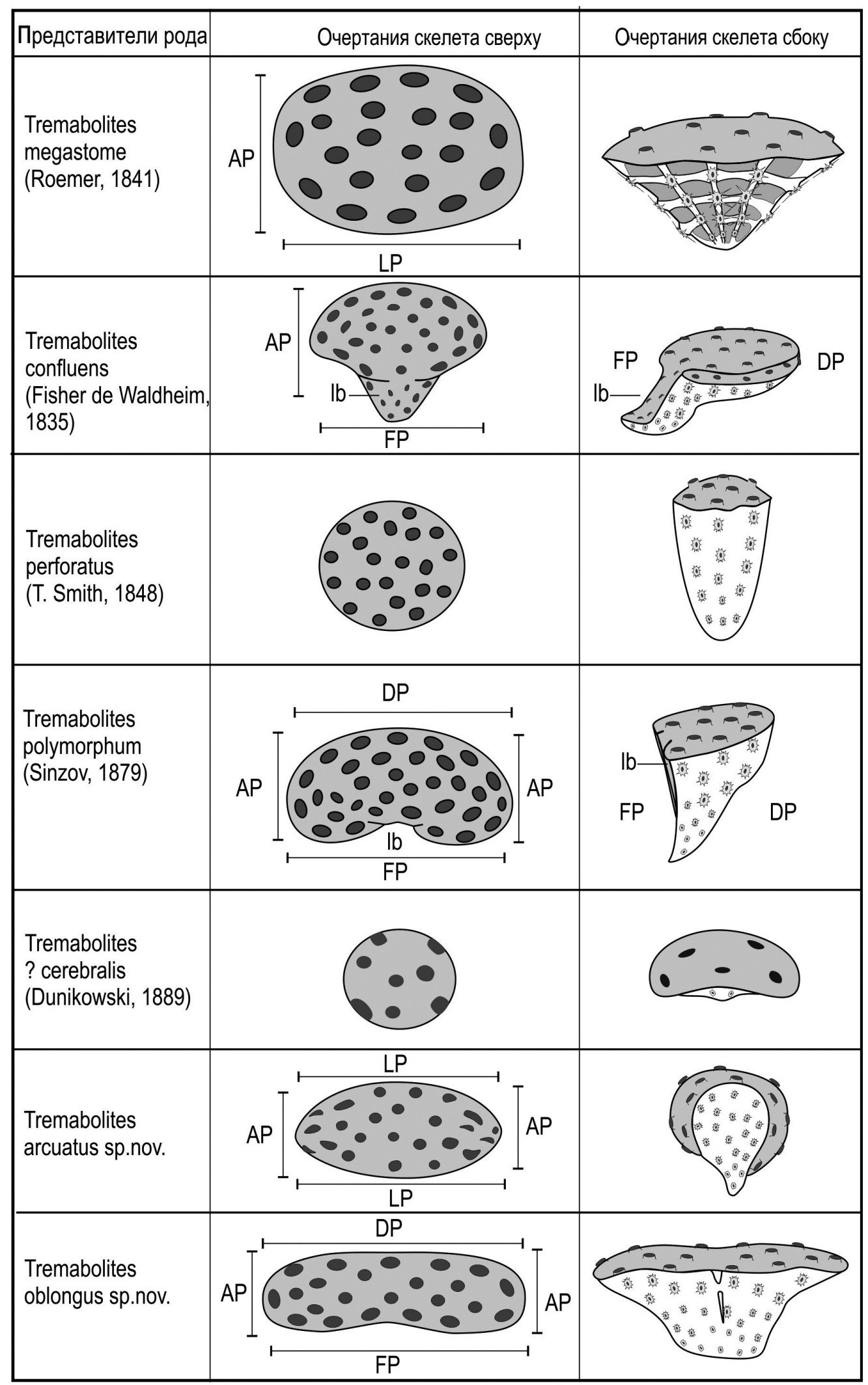

Рис. 2. Особенности строения скелета представителей рода Tremabolites Zittel, 1877. Условные обозначения: AP - ангустатные поверхности (стороны) билатерально-симметричного скелета: FP - фронтальная и DP - тыльная поверхности, LP - латусные поверхности скелета, lb - ложбина. Черный цвет - оскулюмы, темно-серый оттенок - кортикальная мембрана, светло-серый оттенок - нижний сегмент скелета 


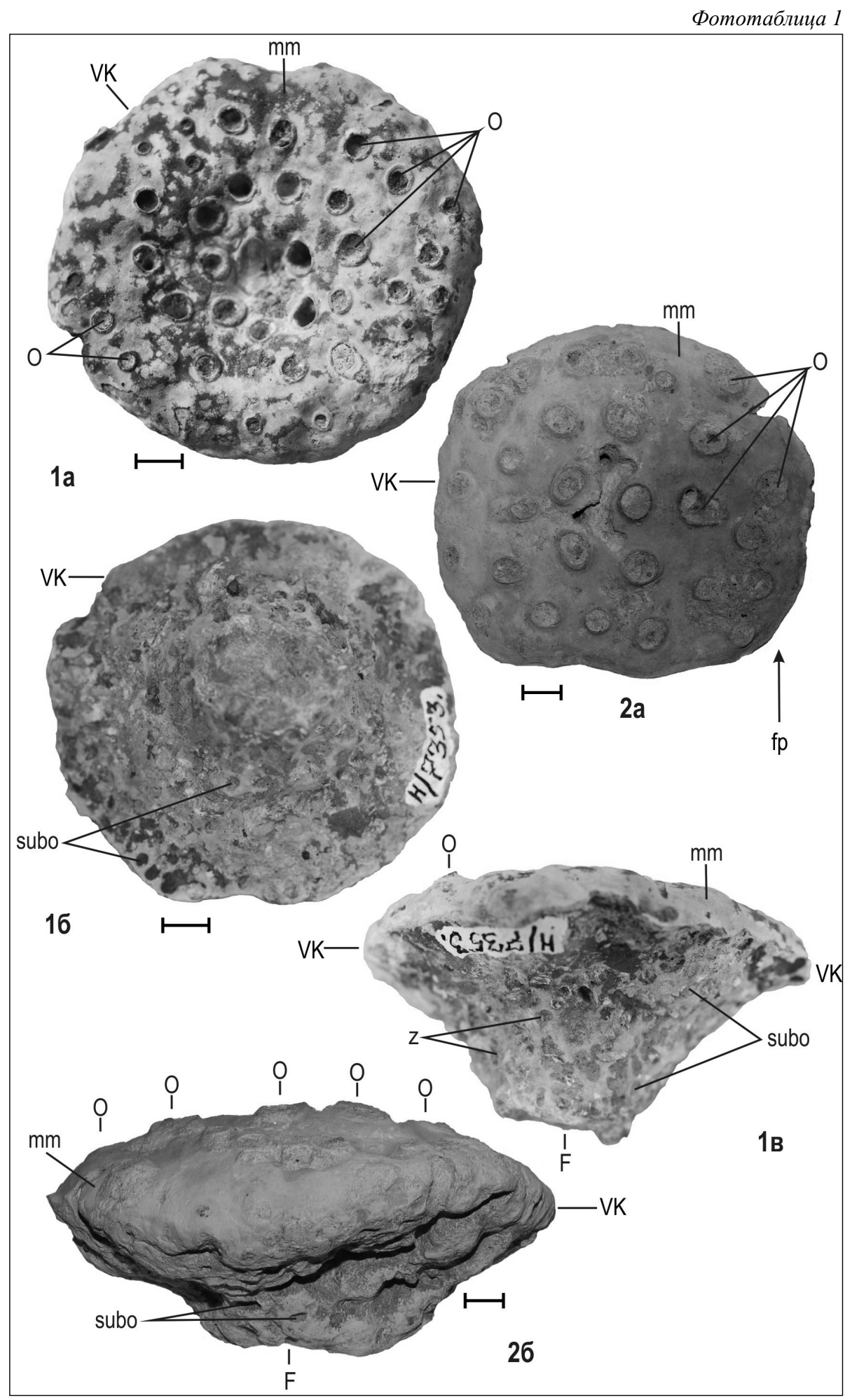

Фототабл. 1. Фиг. 1. Tremabolites megastome (Roemer, 1841). Экз. РЕМ, № 122/7353: изометричный скелет с вогнутой верхней поверхностью; 1а - вид сверху, 16 - снизу, на площадку прикрепления, 1в - сбоку; Саратовская область, Озерки-4; нижний сантон. Фиг. 2. Tremabolites megastome (Roemer, 1841). Экз. PEM, № 121/183: диссимметричный скелет с пологовыпуклой верхней поверхностью, 2а - вид сверху, 2б - сбоку; г. Саратов, Агафоновка; нижний сантон. Условные обозначения: $\mathrm{F}$ - основание скелета, $\mathrm{O}$ - оскулюм, VK - верхний край, $\mathrm{mm}$ - кортикальная мембрана, subo - субоскулюм, $\mathrm{z}$ - зияние, $\mathrm{fp}$ - фронтальный сектор скелета, стрелка отображает предполагаемое направление течения. Отрезок масштабной линейки соответствует 10 мм 


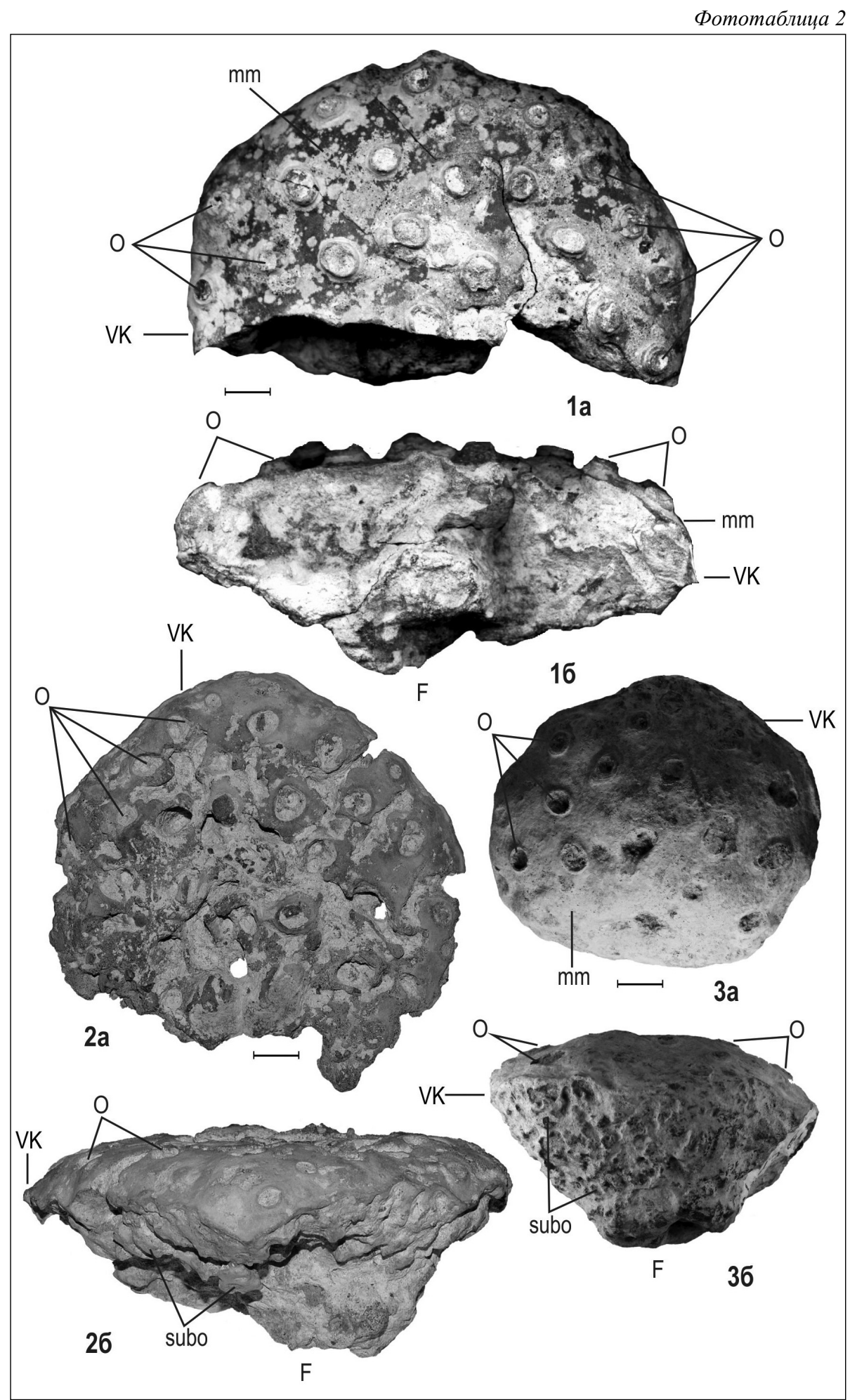

Фототабл. 2. Фиг. 1. Tremabolites megastome (Roemer, 1841). Экз. РЕМ, № 122/436: фрагментированный скелет с пологовыпуклой верхней поверхностью и обособленными оскулюмами: 1а - вид сверху, 16 - сбоку; Саратовская область, Багаевка; нижний сантон. Фиг. 2. Tremabolites megastome (Roemer, 1841). Экз. РЕМ, № 121/829: фрагментированный скелет с плоской верхней поверхностью: 2а - вид сверху, 26 - сбоку; г. Саратов, Агафоновка; нижний сантон. Фиг. 3. Tremabolites megastome (Roemer, 1841). Экз. РЕМ, № 122/4336: изометричный скелет с выпуклой верхней поверхностью: За - вид сверху, 3б - сбоку; Саратовская область, Эстонцы; нижний сантон. Условные обозначения: F - основание скелета, O - оскулюм, VK - верхний край, mm - кортикальная мембрана, subo - субоскулюм.

Отрезок масштабной линейки соответствует 10 мм 


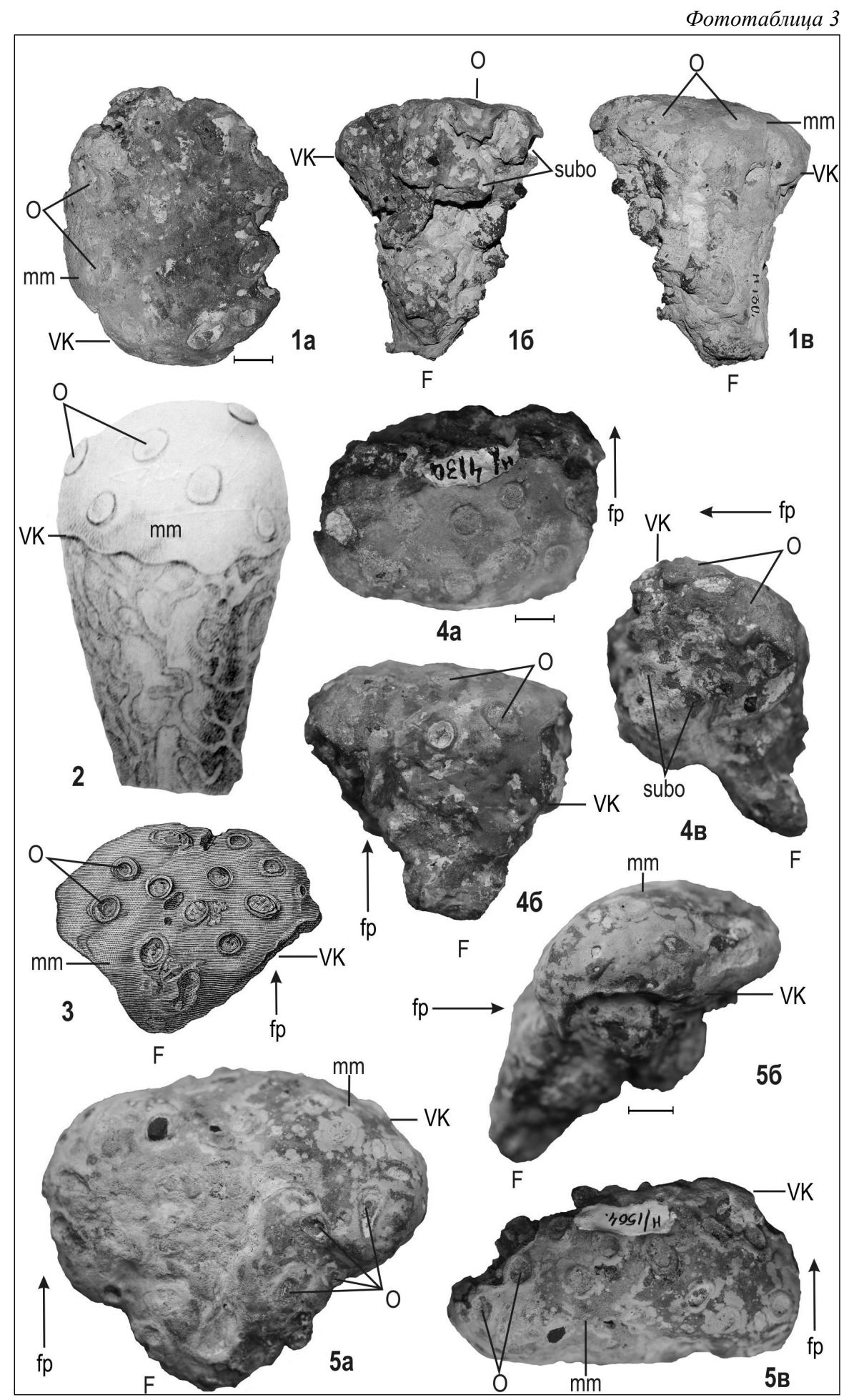

Фототабл. 3. Фиг. 1. Tremabolites perforatus (Т. Smith, 1848). Экз. РЕМ, № 122/130: 1а - вид сверху, 1б, 1в - сбоку, с противоположных сторон; г. Саратов; нижний сантон. Фиг. 2. Tremabolites perforatus (T. Smith, 1848): общий вид скелета (по T. Smith, 1848, Т. 15, с. 294, фиг. 2); Англия; верхний мел. Фиг. 3. Tremabolites confluens (Fisher de Waldheim, 1835): общий вид скелета (по: Лагузен, 1895, с. 83, фиг. 93); г. Саратов; нижний сантон. Фиг. 4. Tremabolites confluens (Fisher de Waldheim, 1835). Экз. PEM, № 122/4130: 4а - вид сверху, 4б - на фронтальную поверхность, 4в - сбоку; Саратовская область, Александровка-3; нижний сантон. Фиг. 5. Tremabolites confluens (Fisher de Waldheim, 1835). Экз. РЕМ, № 122/1564: 5а - вид на фронтальную поверхность, 5б - сбоку, 5в - сверху; Саратовская область, Багаевка; нижний сантон. Условные обозначения: F - основание скелета, O - оскулюм, VK - верхний край, $\mathrm{mm}$ - кортикальная мембрана, subo - субоскулюм, fp - фронтальный сектор скелета, стрелка отображает предполагаемое направление течения. Отрезок масштабной линейки соответствует 10 мм 


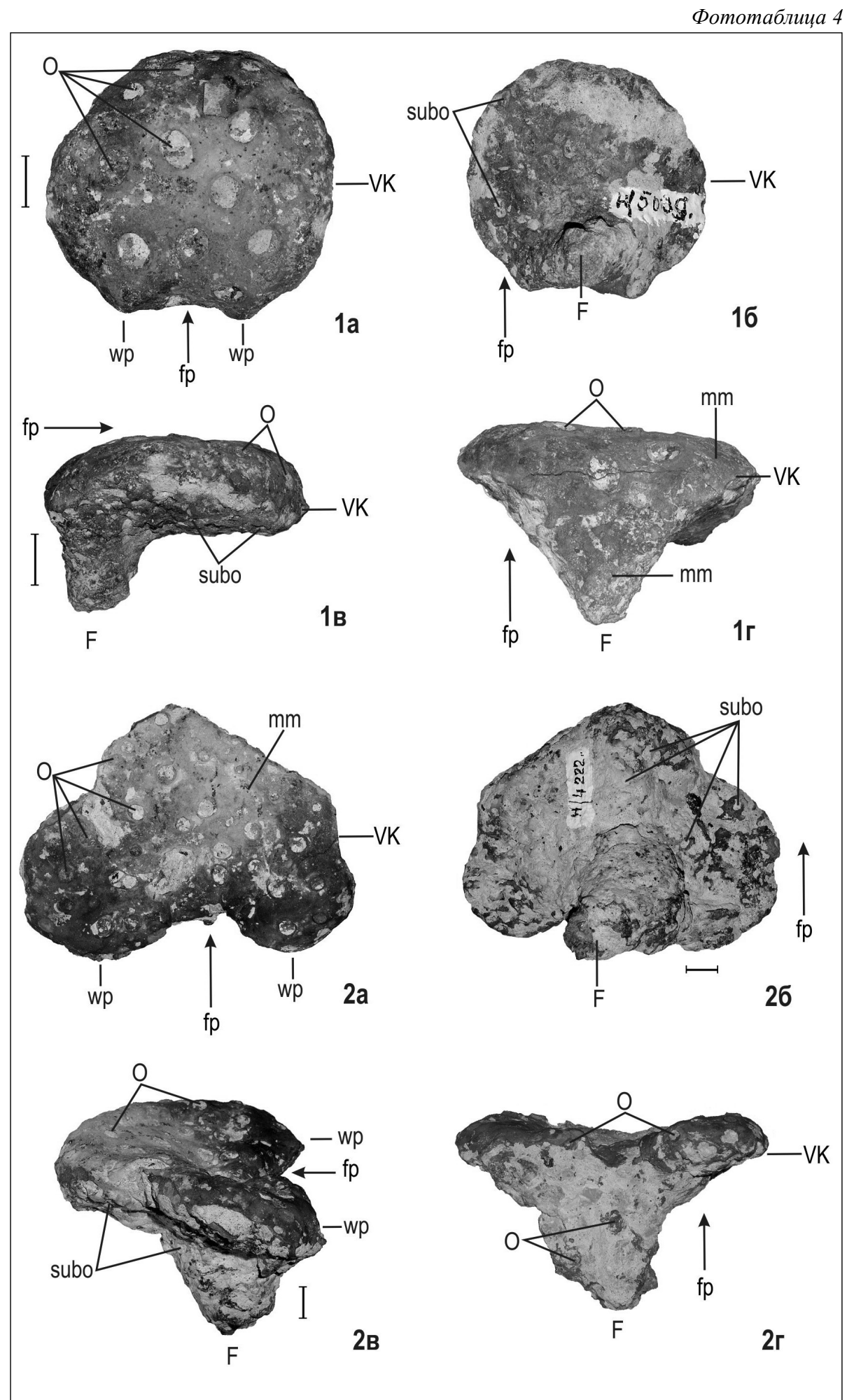

Фототабл. 4. Фиг. 1. Tremabolites polymorphum (Sinzov, 1879). Экз. РЕМ, № 122/5009: 1а - вид сверху, 16 - снизу, 1в - сбоку, 1г - на фронтальную поверхность; Саратовская область, Багаевка; нижний сантон. Фиг. 2. Tremabolites polymorphum (Sinzov, 1879). Экз. PEM, № 122/4222: 2а - вид сверху, 2б - снизу, 2в - сбоку, 2г - на фронтальную поверхность; Саратовская область, Александровка-1; нижний сантон. Условные обозначения: $\mathrm{F}$ - основание скелета, O - оскулюм, VK - верхний край, $\mathrm{mm}$ - кортикальная мембрана, subo - субоскулюм, fp - фронтальный сектор скелета, стрелка отображает предполагаемое направление течения, wp - периферийные крыловидные выросты. Отрезок масштабной линейки соответствует 10 мм 
Фототаблица 5

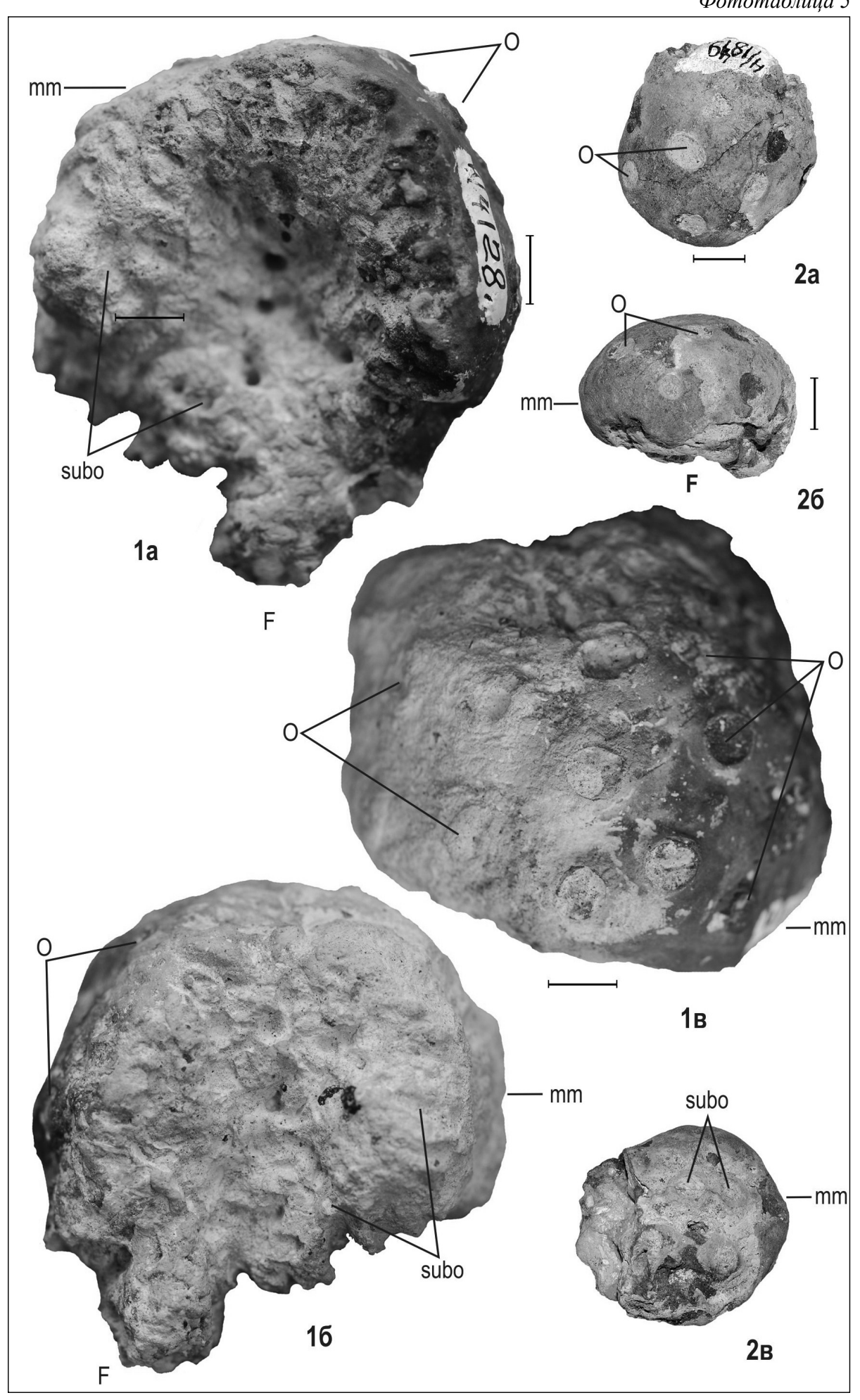

Фототабл. 5. Фиг. 1. Tremabolites arcuatus sp. nov. Экз. РЕМ, № 122/4128: 1a, 16 - противоположные латусные поверхности, 1в - вид на ангустатную поверхность; Саратовская область, Александровка-3; нижний сантон. Фиг. 2. Tremabolites ? cerebralis (Dunikowski, 1888). Экз. РЕМ, № 122/1849: скелет ювенильной особи: 2а - вид сверху, 26 - сбоку, 2в - снизу; г. Саратов; нижний сантон. Условные обозначения: F - основание скелета, O - оскулюм, $\mathrm{mm}$ - кортикальная мембрана, subo - субоскулюм. Отрезок масштабной линейки соответствует 10 мм 


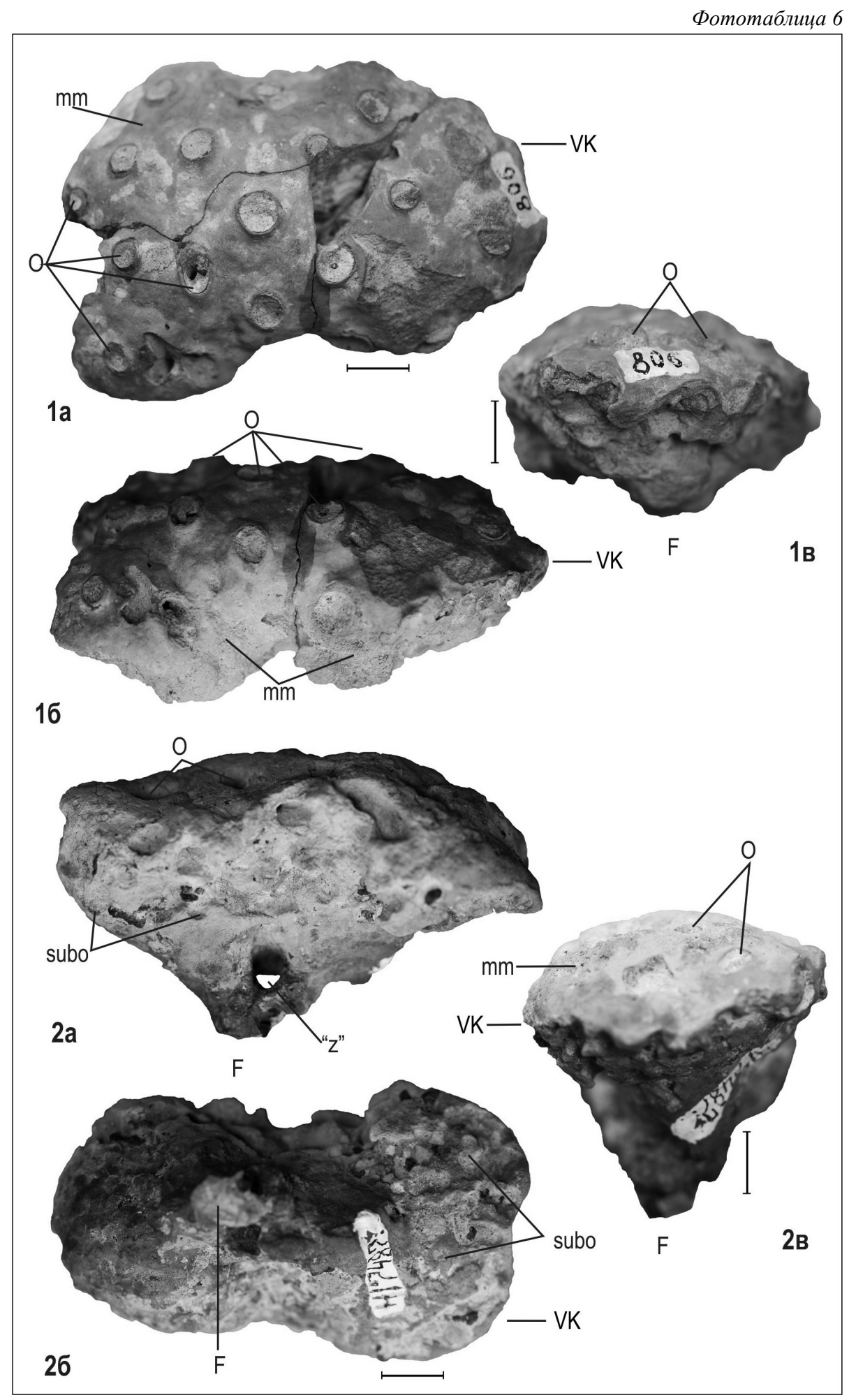

Фототабл. 6. Фиг. 1. Tremabolites oblongus sp. nov. Экз. РЕМ, № 121/806: 1а - вид сверху, 16 - латусная поверхность, 1в - ангустатная поверхность; г. Саратов, Заплатиновка; нижний сантон. Фиг. 2. Tremabolites oblongus sp. nov. Экз. РЕM, № 122/7487: 2a - латусная поверхность, 26 - вид снизу, 2в - ангустатная поверхность; Саратовская область, Александровка-1; нижний сантон. Условные обозначения: $\mathrm{F}$ - основание скелета, $\mathrm{O}$ - оскулюм, $\mathrm{VK}$ - верхний край, mm - кортикальная мембрана, subo - субоскулюм. Отрезок масштабной линейки соответствует $10 \mathrm{Mм}$ 


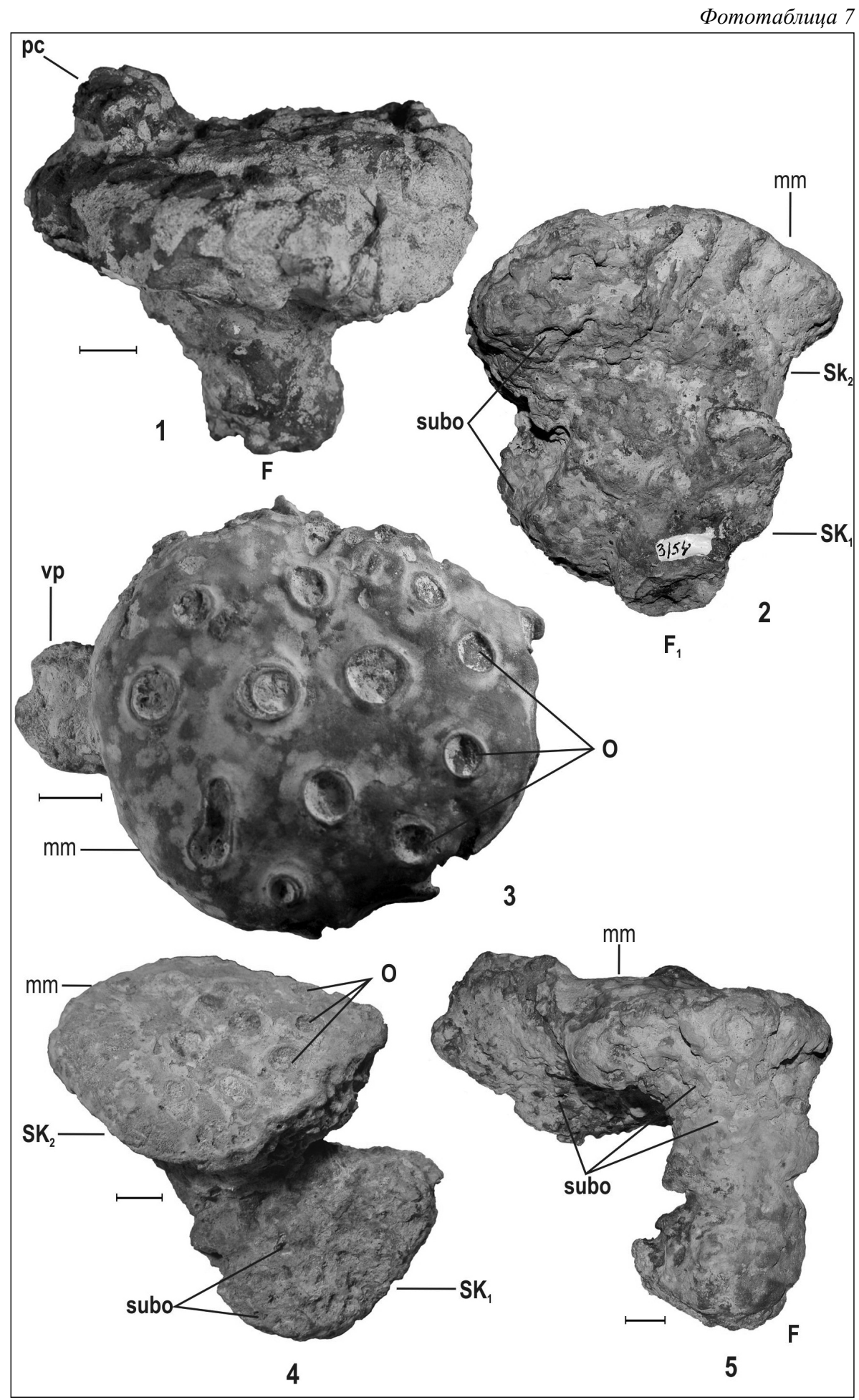

Фототабл. 7. Фиг. 1. Tremabolites megastome (Roemer, 1841). Экз. РЕМ, № 122/3553: вид сбоку; г. Саратов, Заплатиновка; нижний сантон. Фиг. 2. Tremabolites megastome (Roemer, 1841). Экз. РЕМ, № 3/54: вид сбоку, первичный скелет внизу; г. Саратов; нижний сантон. Фиг. 3. Tremabolites megastome (Roemer, 1841). Экз. PEM, № 122/3343: вид сверху; Cаратовская область, Александровка-1; нижний сантон. Фиг. 4. Tremabolites megastome (Roemer, 1841). Экз. ЦНИГРМ, № 10982/177: вид сбоку, первичный скелет внизу; г. Саратов; нижний сантон. Коллекция И. Ф. Синцова. Фиг. 5. Tremabolites sp. Экз. PEM, 122/1377: вид сбоку; г. Саратов; нижний сантон. Условные обозначения: O - оскулюм, $\mathrm{SK}_{1}-$ первичный скелет, $\mathrm{SK}_{2}$ - вторичный скелет, $\mathrm{F}\left(\mathrm{F}_{1}\right)$ - основание (первичного) скелета, $\mathrm{mm}$ - кортикальная мембрана, pc - почка, subo - субоскулюм, vp - вырост. Отрезок масштабной линейки соответствует 10 мм 
терригенным элементам. В этом случае площадка прикрепления достигала 40-50 мм. Вариации горизонтального или вертикального положения площадки прикрепления позволяют предположить, что губки либо крепились к вертикальным объектам, выступающим над поверхностью осадка, либо продольная ось скелета располагалась субгоризонтально.

Онтогенез. Среди Tremabolites установлено проявление почкования. Единичные крупные круглые почки (до 10-15 мм) расположены по периферии верхней поверхности [2]. На их поверхности дермальный кортекс не сохранился (см. фототабл. 7, фиг. 1). В индивидуальном развитии губок меняются соотношение верхней и нижней частей скелета, морфология его верхней части и количество оскулюмов. Скелеты ювенильных губок напоминают нераскрывшиеся бутоны - они небольшие и шарообразные, их поверхность скрыта гладкой кортикальной мембраной с мелкими оскулюмами (см. фототабл. 5, фиг. 2). Лишь в центре основания едва прослеживаются радиально ориентированные мелкие субоскулюмы. На зрелых стадиях развития особей возрастает диаметр верхней поверхности, увеличиваются высота и объем нижней части скелета. Верхняя поверхность становится пологовыпуклой, а в последующем - плоской или вогнутой, количество оскулюмов увеличивается за счет дихотомии несущих ветвей скелета. У некоторых форм обосабливаются отдельные элементы скелета - периферийные фронтальные выросты (Т. polymorphum).

Филогенез. Формирование морфологически обособленных представителей рода от исходно изометричных форм (T. megastome, T. perforatus) предполагается за счет адаптации к условиям ламинарных течений и бокового крепления к твердым элементам субстрата. Асимметрия скелета в этом случае (T. confluens, T. polymorphum) проявлялась в разном строении его противоположных латусных сторон. На фронтальном секторе отчетливо выраженный желоб разделяет крупные периферийные крыловидные элементы скелета.

Регенерационные возможности. Выделены скелеты губок, переживших катаклизмы, обусловленные резким изменением гидродинамики придонной среды. Частичная регенерация проявляется при фрагментации скелета и кратковременном прекращении роста организма, с последующим восстановлением его развития (см. фототабл. 7, фиг. 2). Полная регенерация в данном случае происходила после отрыва губки от поверхности субстрата и при ее переворачивании. От базальной части первичного скелета, которая оказывалась наиболее приподнятой над осадком, формировался новый скелет того же организма (см. фототабл. 7, фиг. 4).

Тафономия. Фоссилии полной хорошей сохранности редки. Основание скелета часто раз- рушено и закрыто фосфатным или кремнистым цементом. Редко и фрагментарно сохраняются субоскулюмы и ажурная сеть выростов нижней поверхности. При разрушении кортикальной мембраны строение сохранившихся фоссилий Tremabolites сходно с морфологией губок Plocoscyphia. Сантонские скелеты Tremabolites фосфатизированы и фрагментированы, в той или иной степени окатаны. Присутствие на поверхности скелетов почкообразных образований свидетельствует о мгновенной фоссилизации губок, послужившей причиной их гибели. На скелетах погибших губок селились мелкие устрицы и брахиоподы.

Сравнение. Типовой род. В работе [11] представлено изображение скелета губки Саmerospongia fungiformis Goldfuss, 1831 с одним центральным оскулюмом и многими субоскулюмами на нижней поверхности, наличие которых не соответствует содержанию рода Camerospongia. Наличие субоскулюмов позволяет предполагать, что эта форма может рассматриваться в составе подсемейства Tremabolitini.

Состав. Tremabolites megastome (Roemer, 1841); T. confluens (Fisher de Waldheim, 1843); T. perforatus (T. Smith, 1848), T. polymorphum (Sinzov, 1879); T. cerebralis (Dunikowski, 1889); T. ? leonardi Schrammen, 1910-12; T. ? ophioides (Defretin-Lefranc, 1958); T. arcuatus sp. nov.; T. oblongus sp. nov.

Распространение. Средний-верхний мел Европы.

\section{Tremabolites megastome (Roemer, 1841)}

Табл. 1, 2; рис. 2.

Manon megastoma - Roemer, 1841, c. 3, табл. 1, фиг. 9.

Camerospongia megastoma - Schluter, 1872, c. $19 ;-$ Leonard, 1897 , c. 36.

Tremabolites megastoma - Zittel, 1877, c. 56; - Schrammen, 1912, с. 317, табл. 39, фиг. 3-5; - Defretin-Lefranc, 1958, с. 93, табл. 14, фиг. 3; Lagneau-Herenger, 1962, с. 115, табл. 17, фиг. 5; - Ulbrich, 1974, c. 65-66; - Malecky, 1980, табл. 10, фиг. 2; - Konig, 1988, с. 39, табл. 5, фиг. 2; Swierczewska-Gladysz, 2006, с. 269-270, фиг. 35c, h; - 2010, с. 269 , фиг. $10 \mathrm{H}$, I. c. 317 .

Tremabolites leonhardi-Schrammen, 1910-12,

Описание. Верхняя часть изометричного скелета круглых и широкоовальных очертаний, основание расположено в центре его нижней невысокой конической части. У крупных форм диаметр скелета по верхнему краю составляет 86-100/90-105 мм, что в 2 раза превышает его высоту (40-47 мм), при количестве оскулюмов до 20-30. Верхняя поверхность ровная плоская или пологовыпуклая, в редких случаях вогнутая. Скелеты мелкоразмерных форм, рассматриваемых как ювенильные, сферических очертаний, большая часть поверхности закрыта кортикальной 
мембраной. Высота скелета этих губок (37-52 мм) немногим меньше его диаметра (45-52/54-62 мм), количество оскулюмов 8-12.

Сравнение. Среди представителей рода выделяется изометричным строением, а от T. perforatus - невысокой ширококонической нижней частью.

Распространение. Неоднозначное понимание содержания вида способствовало формированию представлений о его широком стратиграфическом распространении: апт - альб Испании, апт - коньяк Франции, верхний сеноман - кампан Германии, сеноман Чехии, коньяк - кампан Польши, средний коньяк - сантон Поволжья.

Материал. Более 90 экз. из разрезов: Агафоновка, Лысая гора, Заплатиновка, Новоузенское, Усиевича (г. Саратов); Александровка, Багаевка, Большой Мелик, Карамышка, Мезино-Лапшиновка, Нижняя Банновка, Озерки, Пудовкино, Репная Вершина, Хмелевка, Эстонцы (Саратовская область); Алешники (Волгоградская область); Никольское (Тамбовская область); Новоульяновск (Ульяновская область).

\section{Tremabolites confluens (Fisher de Waldheim, 1843)}

Табл. 3, фиг. 3-5; рис. 2.

Camerospongia megastoma - Schluter, 1872, c. 19, 27, табл. 33, фиг. 6.

Tremabolites confluens - Лагузен, 1895, фиг. 93 , c. 83 .

Non Coeloptychium confluens - Fisher de Waldheim, 1843, с. 669, табл. 16, фиг. 1.

Описание. Скелет каплевидных очертаний, часто искажен. От верхней части скелета, округлой и субплоской, кортикальная мембрана по наклонному узкому фронтальному сектору спускается до его конусовидного основания. Фронтальная поверхность порой осложнена флексурным изгибом. Значения параметров скелета изменяются в широких пределах. Размер верхней части скелета 55-70/70-90 мм, количество оскулюмов 12-23. Высота скелета при его субгоризонтальном положении составляет 40-55 мм. При этом положении скелета площадка приростания к скелетам погибших гексактинеллид ориентирована почти вертикально.

Сравнение. От Т. polymorphum отличается пологим наклоном верхней поверхности фронтального сектора скелета, где расположено его основание, отсутствием периферийных крыловидных выростов.

Замечание. Фишер Вальдхайм представил изображение основания скелета губки, которое все последующее время рассматривается как Etheridgia ex gr. goldfussi (Fischer). Название вида сохранено за формой, изображенной И. Лагузеном [3], со ссылкой на Фишера Вальдхайма.

Распространение. Сантон правобережного Поволжья.

Материал. 62 экз. (аншлифы) из разрезов: Александровка, Багаевка, Большой Мелик, Кара- мышка, Мезино-Лапшиновка, Нижняя Банновка, Озерки, Репная Вершина, Эстонцы (Саратовская область); Агафоновка, Лысая гора, Поливановка и Усиевича (г. Саратов); Алешники (Волгоградская область); Никольское (Тамбовская область); Климовка (Самарская область).

\section{Tremabolites perforatus (T. Smith, 1848)}

Табл. 3, фиг. 1, 2; рис. 2.

Cephalites perforatus - T. Smith, 1848, c. 294, табл. 15, фиг. 2; - Treathis ..., 2004, с. 524, фиг. 344-4.

Описание. Скелет высокий (до 76-80 мм) узкоконический. Верхняя поверхность округлая, диаметром до 53-57/65 мм, плоская и пологовыпуклая. Верхний край нависает над нижней частью скелета. Количество оскулюмов изменяется от 10 до 15.

Сравнение. Среди родственных форм выделяется субцилиндрическим габитусом скелета, округлой верхней поверхностью небольшого диаметра.

Распространение. Альб - сеноман южной Англии, сантон Поволжья.

Материал. 6 экз. из разрезов Саратовской области: Саратов, Александровка, Озерки.

\section{Tremabolites polymorphum (Sinzov, 1879)}

Табл. 4, фиг. 1, 2; рис. 2.

Maeandroptychium polymorphum - Синцов, 1879 , с. 10-11, табл. 1, фиг. 7, табл. 2, фиг. 1.

Описание. Скелет билатерально симметричный, кресловидный, верхняя часть фасолевидных симметричных очертаний. Кортикальная мембрана слагает верхнюю часть скелета и прослеживается по крутонаклонной ложбине в центре фронтального сектора, вплоть до основания скелета. Ложбина разделяет два периферийных крыловидных выроста. Морфологическая выраженность ложбины и обособленность периферийных выростов отчетливо прослеживаются в строении крупных скелетов. Значения параметров скелета также заметно варьируют. Мелкорослые формы высотой 31-35 мм и диаметром выпуклой верхней поверхности 40-50/48-59 мм, с 8-13 оскулюмами. Высота форм средней размерности 45-50 мм, диаметр субплоской неровной верхней поверхности 50-66/62-83 мм, с 14-15 оскулюмами. Крупные скелеты высотой 60-80 мм, диаметр вогнутой верхней поверхности 75-85/106-120 мм, с 1826 оскулюмами. Высота нижней части занимает 75-95 \% всей высоты скелета. Дополнительные опорные элементы отмечены на нижней поверхности скелета, основание которого приурочено к его фронтальному сектору.

Сравнение. От Т. confluens отличается периферийными фронтальными выростами, разделенными субвертикальным желобом.

Распространение. Средний коньяк - сантон Поволжья.

Материал. 36 экз. (аншлифы) из разрезов: 
Александровка, Багаевка, Большой Мелик, Карамышка, Мезино-Лапшиновка, Озерки, Репная Вершина (Саратовская область); Каменный Брод (Волгоградская область); Климовка (Самарская область).

\section{Tremabolites cerebralis (Dunikowski, 1889)} Табл. 5, фиг. 2; рис. 2. c. 83 .

Plocoscyphia cerebralis - Dunikowski, 1889,

Tremabolites cerebralis - Трестьян, 1973, c. 10-11, табл. 1, фиг. 3, 4 .

Tremabolites ophioides - Defretin-Lefranc, 1958, с. 94-95, табл. 14, фиг. 4-7.

Описание. Скелет мелкий, размером с грецкий орех, высотой до 14 мм и диаметром 31/40 мм, количество оскулюмов варьирует от 8 до 20. Очертания скелета полусферические и дисковидные, с выпуклой, реже плоской или вогнутой верхней поверхностью.

Сравнение. От Т. megastome отличается меньшими размерами скелета и оскулюмов.

Замечание. Предполагаем, что в данном случае описаны губки пионерских поселений в сукцессии средне-, позднемеловых спонгиосообществ. Единичные поволжские губки рассматриваются как ювенильные формы: мелкие, округлых очертаний и полностью, за исключением центра основания скелета, закрыты кортикальной мембраной.

Распространение. Верхний сеноман Среднего Приднестровья (71 экз.), верхний турон - средний коньяк Франции, сантон Поволжья.

Материал. 4 экз. из разрезов: Поливановка (г. Саратов); Александровка, Мезино-Лапшиновка, Шклово (Саратовская область).

\section{Tremabolites arcuatus sp. nov.}

Табл. 5, фиг. 1; рис. 2. ный.

Название вида от arcuatus (лат.) - дугообраз-

Голотип - SSU PEM, № 122/4128; Александровка, нижний сантон.

Паратип - SSU PEM, № 122/8732; Александровка, нижний сантон.

Описание. Дугообразные очертания скелета обусловлены сферическим изгибом верхней поверхности, при котором узкие ее сектора почти соприкасаются. Высота скелета 60-80 мм, диаметр 66-75 мм. Протяженность изогнутой верхней поверхности 130-170 мм. Количество оскулюмов изменяется от 20 до 30. Протяженные латусные сектора верхней поверхности нависают над вогнутыми во внутрь участками нижней части скелета. В основании скелета короткий стержнеобразный вырост.

Сравнение. От родственных форм отличается изогнутым, подковообразным строением скелета.

Распространение. Нижний сантон Саратовской области.
Материал. 12 экз. из разрезов: Александровка, Багаевка, Карамышка, Озерки (Саратовская область); Заплатиновка, Поливановка (г. Саратов).

\section{Tremabolites oblongus sp. nov.}

Табл. 6, фиг. 1, 2; рис. 2. ватый.

Название вида от oblongus (лат.) - продолго-

Голотип - SSU PEM, № 121/806; г. Саратов, нижний сантон.

Паратип - SSU PEM, № 122/6532; Александровка; нижний сантон.

Описание. Очертания верхней части низкого (до 40-55 мм) и протяженного в горизонтальной плоскости скелета напоминают батон багет. Высота верхней части до 10-20 мм. Длина продольной оси верхней поверхности достигает 90-105 мм, а короткой - 50-65 мм. Верхняя поверхность пологовыпуклая и неровная, иногда гантелевидных очертаний. Узкие сектора верхней поверхности выпуклые, а широкие сектора протяженные. У некоторых форм по одной латусной стороне кортикальная мембрана спускается вниз. Количество оскулюмов изменяется от 14-15 до 20-25. Нижняя часть скелета коническая, иногда асимметричная и даже скошенная, основание слабо обособлено.

Сравнение. От Т. megastome отличается овально-вытянутыми очертаниями.

Распространение. Нижний сантон Саратовской области.

Материал. 20 экз. из разрезов: Александровка, Озерки, Багаевка (Саратовская область); Алтынка, Заплатиновка, Новоузенское (г. Саратов).

\section{Библиографический список}

1. Первушов E. М. Морфотипы и модульная организация позднемеловых гексактинеллид (Porifera, Hexactinellida). Саратов : Издательство Саратовского университета, 2018. $208 \mathrm{c}$.

2. Первушов Е. М. Проявления почкования среди позднемеловых скелетных губок - гексактинеллид // Изв. Сарат. ун-та. Нов. сер. Сер. Науки о Земле. 2010. Т. 10, вып. 1. C. 51-64.

3. Лагузен И. Краткий курс палеонтологии. Палеозоология. Выпуск первый. Санкт-Петербург : Типография Императорской Академии наук, 1895. 326 с.

4. Основы палеонтологии. Губки. Археоциаты. Москва : Издательство АН СССР, 1962. 485 с.

5. Синцов И. Ф. О меловых губках Саратовской губернии // Записки Новороссийского общества естествоиспытателей. Т. 6, вып. 1. Одесса : Издательство Ульриха, 1879. С. 1-40. 6. Трестьян Г. Н. Характеристика позднемеловых губок Среднего Приднестровья // Палеонтология и стратиграфия мезокайнозоя южных окраин Русской платформы. Кишинёв : Издательство «Штиинца», 1973. С. 3-15.

7. Fischer de Waldcheim G. Sur Quelques polypiers fossiles du gouvernement de Moscou // Bulletin de la Société Impériale des Naturalistes de Moscou. 1843. T. 16, № 4. P. 663-670. 
8. Defretin-Lefranc $S$. Contribution a l'etude des spongiaires siliceux du Cretace superieur du Nord de la France - These Presentee a la Faculté des sciences de Lille pour obtenir le grade de Docteur es sciences Naturelles. Lille : Universite de Lille, $1958.178 \mathrm{p}$.

9. Dunikowski E. O gabkach cenomanskich z warstwy fosforytowei Podola Calicyiskiego // Pamietnik Akademii umiejetnosci, Krakowie. 1888. T. 16. P. 70-87.

10.Konig $W$. Die Schwamme des Campans von Misburg und Hover // Arbeitskreis Palaontologie Hannover. 1988. Bd. 16. S. 35-49.

11.Krupp R. Cameroptychium scharnhorsti n.sp., ein hexactinellider Schwamm aus dem Unteren Campan von Höver, Niedersachsen // Arbeitskreis Paläontologie Hannover. 2010. Bd. 38. S. 46-58.

12.Lagneau-Herenger L. Contribution a l'etude des spongiaires siliceux du Cretace inffrieur // Memoire de la Societe Geologique de France, Nouvelle Serie, Paris. 1962. T. 41, № $95.252 \mathrm{p}$.

13.Leonard R. Die Fauna der Kreideformation in Oberschlesien // Paleontographica, Stuttgart. 1897. T. 44. S. 11-70.

14.Malecki J. Santonian siliceous sponges from Korzkiew near Krakow (Poland) // Rocznik Polskiego towarzystwa geologicznego. 1980. № 3-4. P. 409-430.

15.Roemer F. A. Die Versteinerungen des norddeutschen Kreidegebirges. Hannover, 1841. $145 \mathrm{~s}$.

16.Schluter C. Uber die Spongitarienbanke der oberen Qadraten- und unteren Mucronaten-Schichten des Munsterlandes //
Festschrift fur 20 Hauptvers de Deutschen Geologischen Gesellschaft zu Bonn. Bonn, 1872. S. 71-82.

17.Schrammen A. Die Kieselspongien der Oberen Krede von Nordwest-Deutschland - Paleontographica. Stuttgart, 1912. Bd. $5.385 \mathrm{~s}$.

18.Smith T. On the Ventriculitidae of the Chalk their classification // Annals and Magazine of Natural History. Ser. 2, London. 1848. Vol. VI. P. 279-295.

19.Swierczewska-Gladysz E. Late Cretaceous siliceous sponges from the Middle Vistula River Valley (Central Poland) and their palaeoecological significance // Annales Societatis Geologorum Poloniae. 2006. Vol. 76. P. 227-296.

20.Swierczewska-Gladysz E. Hexactinellid sponges from the Santonian deposits of the Krakow area (Southern Poland) // Annales Societatis Geologorum Poloniae. 2010. Vol. 80. P. 253-284.

21.Tate $R$. On the correlation of the Cretaceous formations of the north-east of Ireland // Quarterly Journal of the Geological Society of London, London. 1864. Vol. 21. P. 15-46.

22.Treathis on Inverterbrate Paleontology. Part E (Revised), Porifera. Porifera // The Geological Society of America \& The University of Kansas. 2004. Vol. 3. 872 p.

23.Ulbrich H. Die Spongien der Usenburg-Entwicklung (obers unter-Campan) der Subherzynen Kreidemulde // Paleontologi, Leipzig. 1974. Bd. 291. $173 \mathrm{~s}$.

24.Zittel K. A. Studien uber fossile Spongien. Hexactinellidae // Abhandlungen der Koniglichen Bayerischen Akademie der Wissenschaften, Mathematisch-Physische Klasse, Munchen. 1877. Bd. 13. $63 \mathrm{~s}$.

Поступила в редакцию 12.01.2021, после рецензирования 11.01.2021, принята к публикации 15.03.2021

Received 12.01.2021, revised 11.01.2021, accepted 15.03.2021 